\title{
Research on Stretch Forming Process of the Discrete Clamp for Complex Curved Parts
}

\author{
Yanyan CHENG*, Jian XING**, Boyang ZHANG*** \\ *College of Mechanical and Electrical Engineering, Jilin Institute of Chemical Technology, Jilin 132022, \\ People's Republic of China \\ **Energy and Environment Engineering Institute, Nanchang Institute of Technology, Nanchang 330044, \\ People's Republic of China, E-mail: 13843225230@163.com (Corresponding author) \\ ***College of Mechanical and Electrical Engineering, Jilin Institute of Chemical Technology, Jilin 132022, \\ People's Republic of China \\ crossref http://dx.doi.org/10.5755/j02.mech.30714
}

\section{Introduction}

The skin part, as the main part of aerodynamic configuration of the aircraft, is characterized by small quantities, large varieties and large size. The skin parts are mainly formed by stretch forming and stamping forming [1-3]. Compared with the stamping forming, the stretch forming boasts the advantages of simple die manufacturing, small springback and high forming precision [4]. With the rapid development of the aerospace industry, the profile of skin parts is becoming increasingly complex, and the requirement of forming precision is becoming higher and higher [5-7]. What the traditional stretch forming method uses is the integral clamp. In the process of stretch forming, overall displacement of the clamp takes place. When parts with large curvature or complex curvature are being formed, it is difficult for the sheet metal to fit the die completely, and even it is easy to crack. In addition, in order to promote the sheet metal to fit the die better, a large material transition zone is needed, which leads to low material utilization. Therefore, a new stretch forming process is needed to address the problems of die fitting difficulty and low material utilization.

Discrete clamp stretch forming is a flexible stretch forming process, whose design idea is to use multiple discrete sub-clamps instead of rigid integral clamps (as shown in Fig. 1), and realize flexible self-coordination of multiple sub-clamps with the hydraulic drive technology [8]. The stretch forming process of the discrete clamp is shown in Fig. 2. During clamping, multiple clamps are arranged in a straight line. During forming, multiple clamps can automatically adjust the rotation angle and stretching amount of the jaw according to the change of the die profile, so that the arrangement of the sub-clamps can be consistent with the curvature change of the die profile, and the sheet metal can fit the die more easily [9-10], which changes the overall motion mode of the traditional clamp, reduces the tendency of cracking, downsizes the material transition zone and improves the material utilization rate [11]. Discrete clamp stretch forming is a complex process, and it is necessary to predict, analyze and optimize actual problems through finite element methods. There are many numerical simulation methods for sheet metal forming, among which the elastoplastic finite element method is widely accepted. In the numerical simulation research of stretch forming, many scholars at home and abroad have mainly focused on simple three- dimensional surfaces such as cylindrical parts and spherical parts, but there are few researches on complex curved parts. In this paper, the trapezoidal profile part and the double curved top part are taken as the research objects. With the finite element numerical simulation method, the process of stretch forming of complex curved surface parts with the discrete clamp and the integral clamp is compared and analyzed, and related experiments are carried out. The research results expand the application scope of the discrete clamp stretch forming, which provides certain reference for the stretch forming of other complex profile parts.

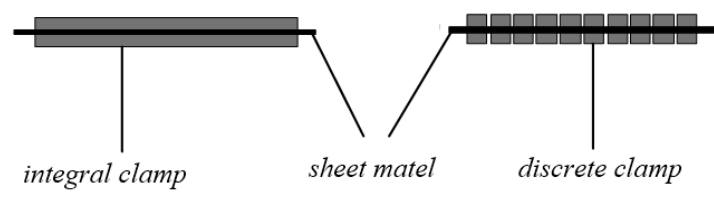

a

b

Fig. 1 Clamp diagram: a) integral clamp; b) discrete clamp

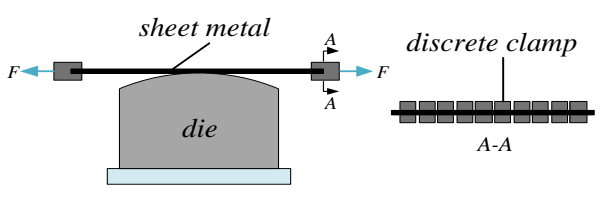

a

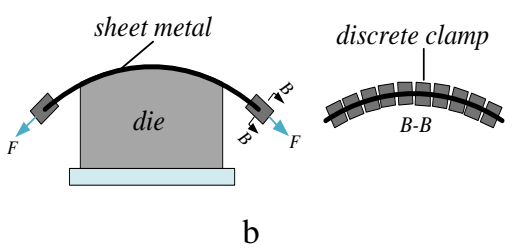

Fig. 2 Forming process: a) before forming; b) after forming

\section{Finite element model}

The finite element models of integral clamp stretch forming and discrete clamp stretch forming are established for trapezoidal profile parts and double curved top parts respectively with the finite element analysis software ABAQUS.

Depending on the target part the dimension of the trapezoidal die was selected, Fig. 3 shows the trapezoidal die. The long side of the die is $1600 \mathrm{~mm}$ long, the short side is $1100 \mathrm{~mm}$ long and the width is $1400 \mathrm{~mm}$. The surface curvature of the long side and the short side is $R_{1}=1700 \mathrm{~mm}$ and $R_{2}=900 \mathrm{~mm}$ respectively, and the surface 
curvature in the width direction is $R_{3}=6000 \mathrm{~mm}$.

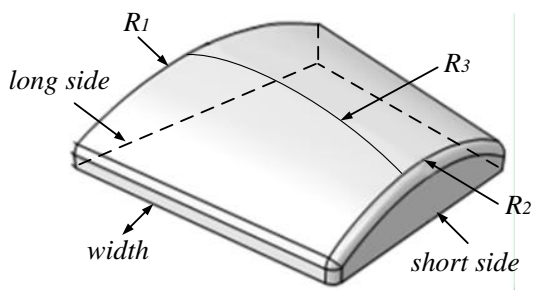

Fig. 3 The trapezoidal die

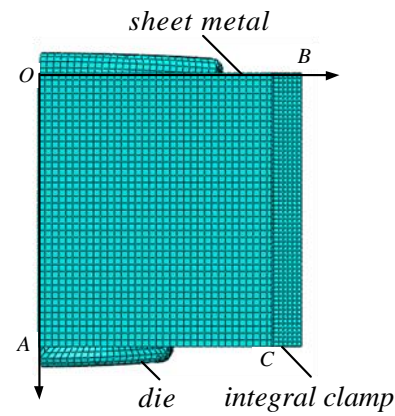

$\mathrm{a}$

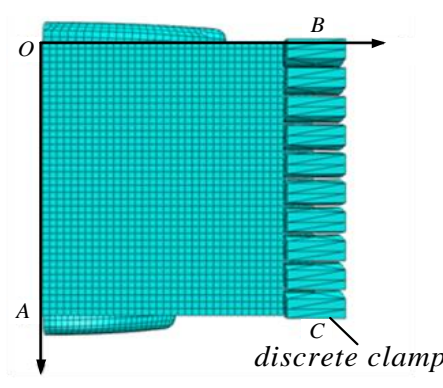

$\mathrm{b}$

Fig. 4 Finite element model (1/2) of trapezoidal profile parts: a) integral clamp; b) discrete clamp

Fig. 4, a shows the finite element model of the integral clamp stretch forming of trapezoidal profile parts, the forming force is applied to the integral clamp. Fig. 4 , b shows the finite element model of the discrete clamp stretch forming, the forming force of each sub-clamp is the same, and sub-clamps are able to automatically move according to the shape of the die. Due to the symmetry of the model, the $1 / 2$ finite element model is established in order to save the calculation time. The sheet metal is made of low carbon steel ST14 with size of $2300 \times 1200 \times 1.5 \mathrm{~mm}$. The density of ST14 is $7850 \mathrm{~kg} / \mathrm{m}^{3}$, the elastic modulus is $207 \mathrm{GPa}$, the Poisson ratio is 0.28 , and the yield stress is 176.3 $\mathrm{MPa}$. The sheet metal is assumed to be isotropic and obeys the Von Mises yield criterion. The quadrilateral shell element S4R is used to divide the grid. The discrete clamp consists of 10 sub-clamps on one side. The four-node 3D rigid body element R3D4 is adopted for meshing of the clamp and the die. The contact pairs between the sheet metal and the die and the clamp are formed respectively, and the general contact algorithm is adopted. The Coulomb friction model is used for the contact between the sheet metal and the die, and the friction coefficient is 0.15 ; the friction between the sheet metal and the clamp is assumed to be infinite, and the Rough model is adopted. The relevant boundary conditions are set for parts. Symmetrical boundary constraints are imposed on the symmetry axis of the sheet metal, and all degrees of freedom for die are con- strained. The loading of tensile force is realized by the connecting unit in the software. In the figure, OA is the direction of symmetry axis of the formed part, $\mathrm{OB}$ is the direction of the long side of the die, and $\mathrm{AC}$ is the direction of the short side.

Fig. 5, a shows the hyperbolic top die, where the curvature radius of the small curved part is $R_{1}=390 \mathrm{~mm}$, the curvature radius of the large curved part is $R_{2}=560 \mathrm{~mm}$, the curvature radius of the transition is $R_{12}=580 \mathrm{~mm}$, other dimensions are $L_{1}=350 \mathrm{~mm}, L_{2}=960 \mathrm{~mm}$, and $L_{3}=900 \mathrm{~mm}$. The die is symmetrical, and the $1 / 2$ finite element model is established, as shown in Fig. 5, b. The selected simulation material is low carbon steel ST14 sheet metal with the size of $2000 \times 1200 \times 1.5 \mathrm{~mm}$, and other parameters are the same as those of the trapezoidal profile part model.

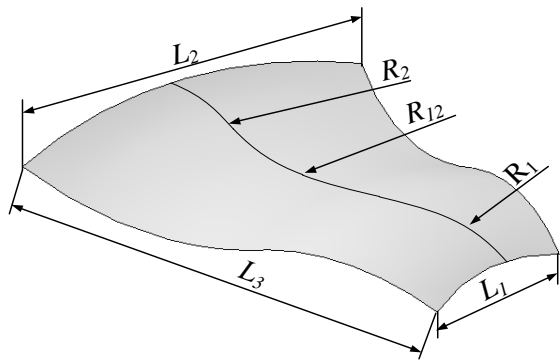

a

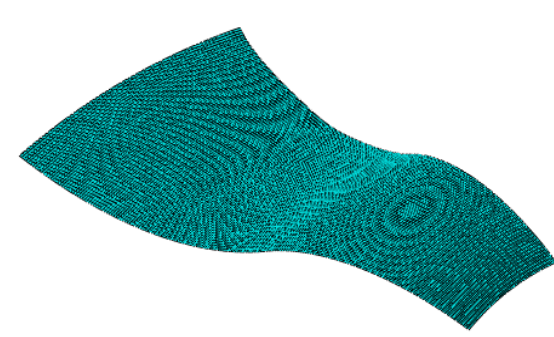

b

Fig. 5 The hyperbolic top die: a) schematic diagram of hyperbolic top die; b) finite element model (1/2)

\section{Numerical simulation analysis of the trapezoidal pro- file part}

\subsection{Formability analysis}

Numerical simulation of the integral clamp and the discrete clamp stretch forming of the trapezoidal profile part is carried out. The horizontal force and vertical force of the integral clamp are $220 \mathrm{kN}$ and $290 \mathrm{kN}$ respectively. The discrete clamp has 10 sub-clamps on one side, so the horizontal force and vertical force of a single clamp are $22 \mathrm{kN}$ and $29 \mathrm{kN}$ respectively. Fig. 6 shows the illumination pattern of the formed part. As shown in the figure, the sheet metal does not fully fit the die when the integral clamp is used, while it can fully fit the die when the discrete clamp is used. The reason is that the initial fitting position between the sheet metal and the die is on the long side, and then the fitting area gradually transits to the short side. Since the displacement at any part during the forming process of the integral clamp is the same, the part of the sheet metal which has been fitted will continue to be stretched synchronously during the fitting process, which increases the resistance of clamp movement, so it is not easy for the sheet metal to fit the die. When the discrete clamp is used, the movement of each sub-clamp is inde- 
pendent, and corresponding displacement can be produced with the change of the curvature of the die edge, which avoids the synchronous stretching of all parts of the sheet metal, reduces the resistance of clamp movement, so that the sheet metal is more evenly stressed and it is easier for the sheet metal to fit the die.

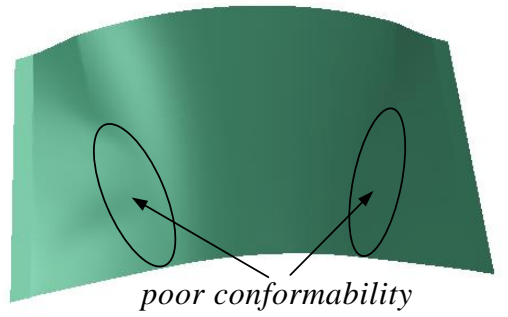

a

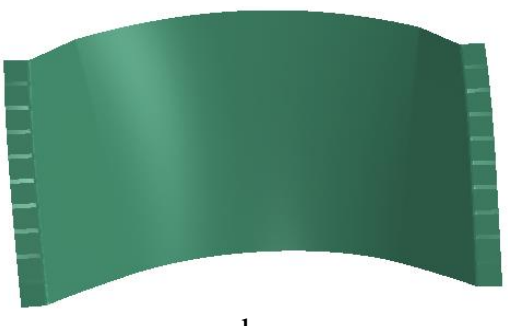

b

Fig. 6 The illumination pattern of the formed part: a) integral clamp; b) discrete clamp

\subsection{Strain analysis}

When the horizontal force remains unchanged and the vertical force increases to $310 \mathrm{kN}$, the sheet metal formed by the integral clamp can fit the die completely. Fig. 7 shows the strain distribution when the formed part fits the die completely. As shown in Fig. 7, the maximum strain of the formed part corresponding to the integral clamp and the discrete clamp is 0.2753 and 0.1541 respec-

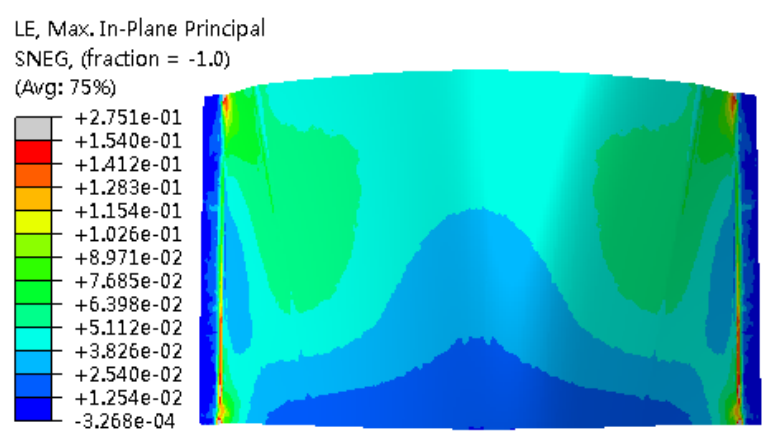

$\mathrm{a}$

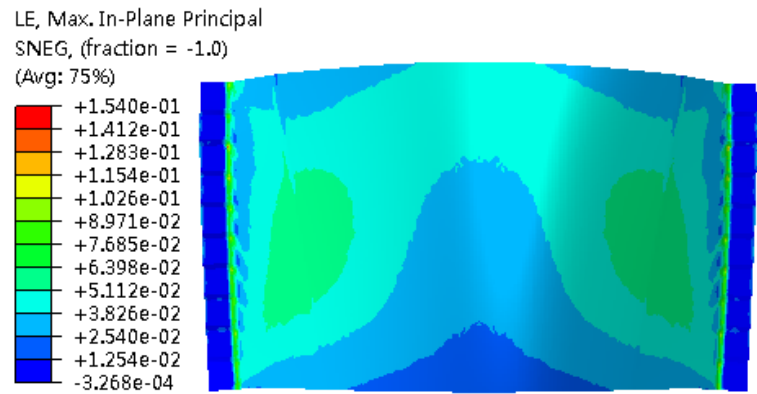

$\mathrm{b}$

Fig. 7 The strain distribution of formed parts: a) integral clamp; b) discrete clamp tively. and the maximum strain of the former is $44.03 \%$ greater than that of the latter. The position where the maximum strain occurs is at the edge of the sheet metal clamped by the clamp on the long side of the die. This is because the sheet metal at this position first fits the die during forming, and the material at this position is subject to the maximum tensile force when the sheet metal fully fits the die, so the strain is the largest. Under the clamping of the integral clamp, all parts of the sheet metal are stretched synchronously. However, use of the discrete clamp avoids synchronous stretching of all parts of the sheet metal. Therefore, the maximum strain of the discrete clamp is much smaller than that of the integral clamp. In addition, the maximum strain values in the effective forming zone of the formed part corresponding to the integral clamp and the discrete clamp are 0.0636 and 0.0608 respectively, and the minimum values are 0.0122 and 0.0173 , respectively. The strain distribution range of the discrete clamp is smaller and the distribution is more uniform.

\subsection{Thickness distribution}

Fig. 8 shows the thickness distribution of the trapezoidal profile part. As shown in the figure, the thickness distribution trend of the formed part is roughly the same as that of the strain distribution (Fig. 7), which is because the greater the strain change, the greater the thickness change. In the effective forming zone of the formed part, the maximum thickness corresponding to the integral clamp and the discrete clamp are $1.491 \mathrm{~mm}$ and $1.487 \mathrm{~mm}$ respectively, the minimum thickness is $1.442 \mathrm{~mm}$ and $1.454 \mathrm{~mm}$ respectively, and the maximum thinning value of the former is $20.69 \%$ greater than that of the latter. Therefore, compared with the integral clamp, the thickness distribution range corresponding to the discrete clamp is smaller, and the thickness distribution is more uniform in the effective forming zone.

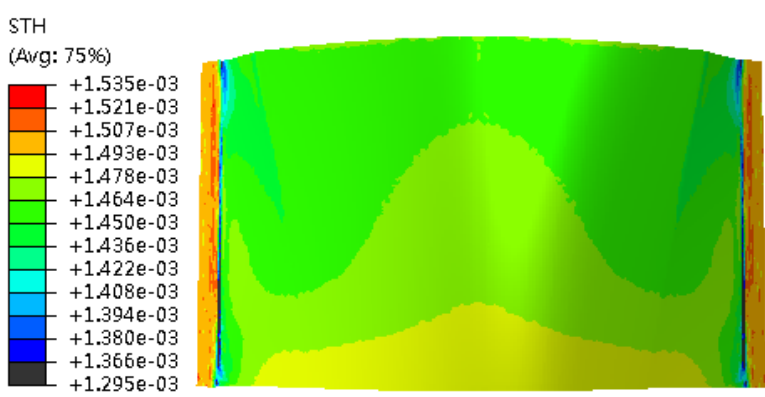

a

STH

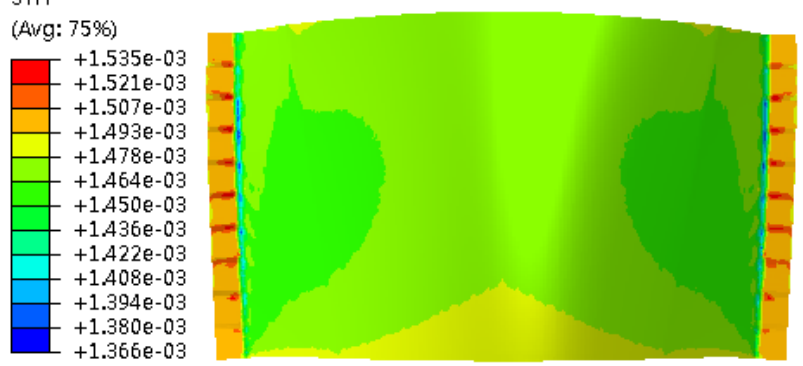

b

Fig. 8 The thickness distribution of formed parts: a) integral clamp; b) discrete clamp 


\subsection{Forming test}

In view of the existing test conditions, there is a newly developed discrete clamp stretch forming device in the laboratory (as shown in Fig. 9, a), the discrete clamp stretching forming test is carried out for the trapezoidal profile part to verify whether the forming effect is consistent with the numerical simulation results.

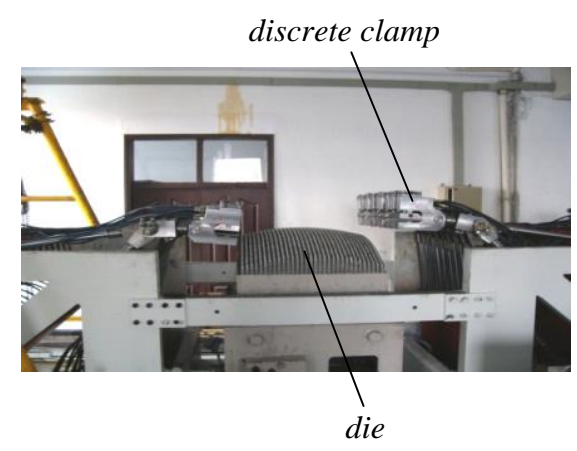

a

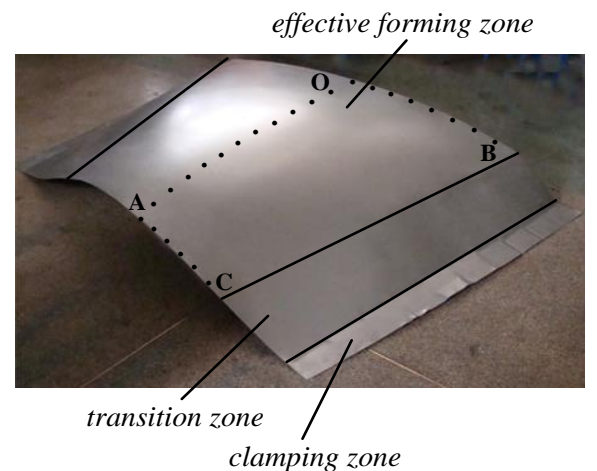

$\mathrm{b}$

Fig. 9 The test device and forming part: a) The discrete clamp stretch forming device; b) the trapezoidal profile part (the discrete clamp)

The test material is ST14, and the dimensions of sheet metal and the die are the same as those of numerical simulation. After forming, the sheet metal and the die can fit perfectly, and the forming effect is good. The test part is shown in Fig. 9, b, and the surface of the effective forming zone is smooth without wrinkling and cracking. The illumination pattern of the test part is consistent with that of the formed part during the numerical simulation (Fig. 6, b).

Thickness measurement is used to verify whether the thickness distribution of test part conforms to the numerical simulation results. Thickness of test part is measured with ultrasonic thickness gauge, the measurement accuracy is $0.001 \mathrm{~mm}$, the accuracy is high. Along three directions of $\mathrm{OA}, \mathrm{OB}$ and $\mathrm{AC}$, the measurement positions of the thickness are consistent between the test part and the numerical simulation part, as shown in Fig. 9, b, and the distance between the measuring points is $100 \mathrm{~mm}$. The thickness values of the same positions on the numerical simulation part are extracted and compared with the measured values. The comparison results are shown in Fig. 10.

As shown in Fig. 10, the measured thickness values along $\mathrm{OA}, \mathrm{OB}$ and $\mathrm{AC}$ directions are slightly less than the numerical simulation values, maximum thickness reduction decreases by $0.17 \%, 0.27 \%$ and $0.06 \%$ respectively, but the change trend of the thickness of the test part is consistent with that of the numerical simulation part, which indicates the correctness of the numerical simulation. The thickness deviation of test part and simulation formed part may be caused by many factors, such as the difference of lubrication conditions, the batch of the sheet metal and the fluctuation of material properties. In engineering applications, the deviation is generally considered to be acceptable within $-20 \% \sim+20 \%$. To sum up, the thickness deviation is very small and within the allowable range.

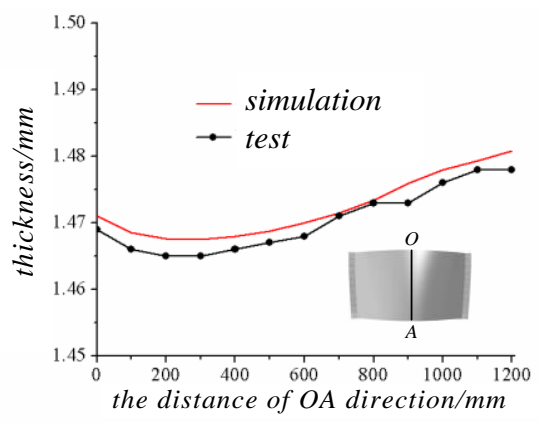

a

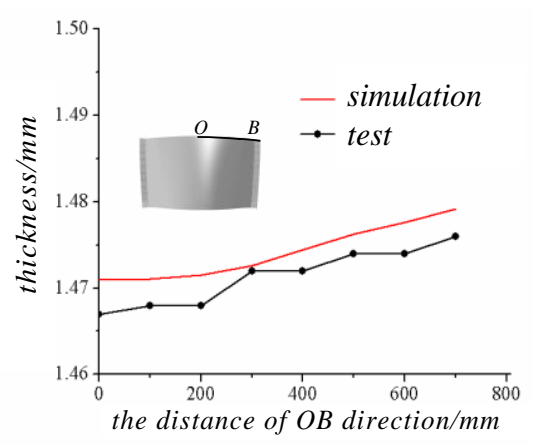

$\mathrm{b}$

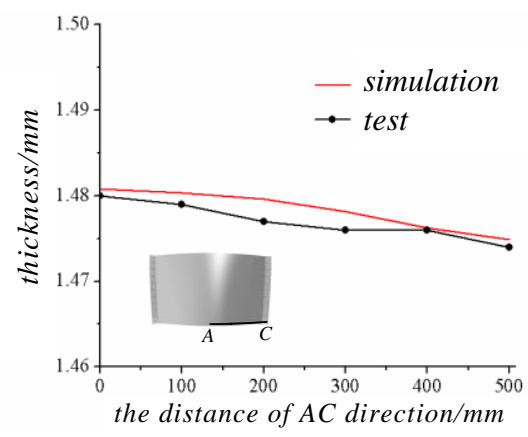

c

Fig. 10 The thickness contrasting curves of experiment and simulation parts: a) the thickness of OA direction; b) the thickness of $\mathrm{OB}$ direction; c) the thickness of $\mathrm{AC}$ direction

\section{Numerical simulation analysis of the double curved top part}

\subsection{Formability analysis}

Numerical simulation of the integral clamp and the discrete clamp stretch forming of the double curved top part is carried out. First, the horizontal force is choosing according to the tensile rate of the sheet metal, and then the vertical force is obtained by trials. Finally, the horizontal force and the vertical force of the integral clamp are $190 \mathrm{kN}$ and $380 \mathrm{kN}$ respectively. The discrete clamp has 
10 sub-clamps on one side, and the horizontal force and the vertical force of a single clamp is $19 \mathrm{kN}$ and $38 \mathrm{kN}$ respectively. The formed part of numerical simulation is shown in Fig. 11. As shown in the figure, a large area of sheet metal does not fit the die for the formed part corresponding to the integral clamp, and the unfitted position is in the concave curvature area of the die. The sheet metal of the formed part corresponding to the discrete clamp fits perfectly with the die, and there is no crack in the sheet metal and no wrinkling in the forming area. In order to make the sheet metal stretched by the integral clamp fit the die, the forming force is increased until the material stretch limit, and the sheet metal still cannot fit the die completely. The above phenomenon is due to the change of convex and concave profile curvature of the double curved top part. The integral clamp is a rigid straight clamp, which has poor adaptability to the change of die curvature. Due to the existence of the double curved top, the sheet metal is difficult to fit the concave curvature part in the middle of the die. However, the discrete clamp has high flexibility, and each sub-clamp can be distributed with the change of die profile, so it is easy to fit the die.

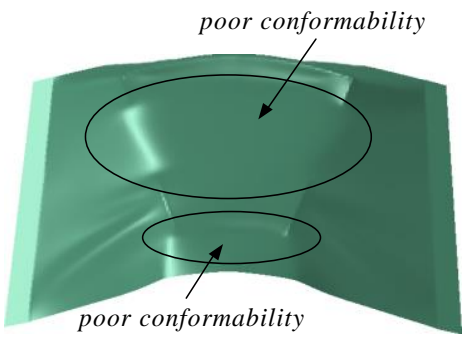

a

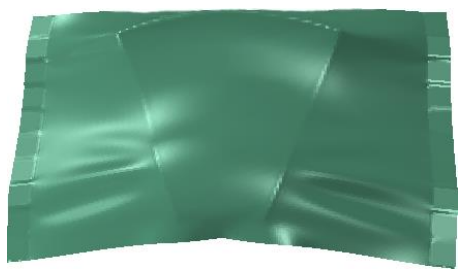

b

Fig. 11 The illumination pattern of the double curved top part: a) integral clamp; b) discrete clamp

The forming effect of these two kinds of clamps can be further compared by change of the vertical displacement of the sheet metal. Fig. 12 shows the vertical displacement distribution of the formed part. Fig. 12, a shows the vertical displacement distribution of the sheet metal when the forming force is close to the stretch limit of the material, and the integral clamp is used. Fig. 12, b shows the vertical displacement distribution of the sheet metal when it just fits the die completely, and the discrete clamp is used. As suggested by the comparison, in the concave curvature part of the forming area, the vertical displacement of the sheet metal corresponding to the discrete clamp is larger, which indicates that the sheet metal corresponding to the discrete clamp can fit the die well, while the sheet metal corresponding to the integral clamp does not fully fit the die. In the clamping area, the vertical displacement of the sheet metal corresponding to the integral clamp is large, which indicates that the sheet metal is much stretched and is easy to crack.

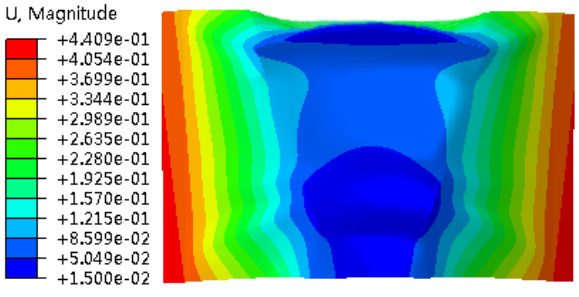

a

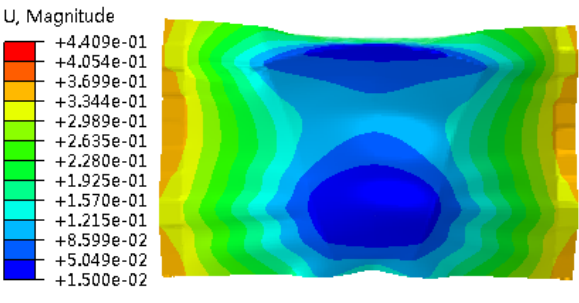

b

Fig. 12 The displacement distribution of formed parts/mm: a) integral clamp; b) discrete clamp

\subsection{Strain and thickness analysis}

It is impossible to get a double curved top part which is well formed with the integral clamp stretch forming, so only the strain and thickness change of the formed part corresponding to the discrete clamp is analyzed.

Fig. 13, a shows the strain distribution of the formed part with the discrete clamp stretch forming. As shown in the figure, the maximum strain in the effective forming zone of the formed part is 0.0778 , which is within the allowable range of the material stretch. Fig. 13, b shows the strain distribution curve of the double curved top part along the $y$ direction of the symmetry axis. The strain value increases first, then decrease and then increases, which is consistent with the change trend of the die curvature.

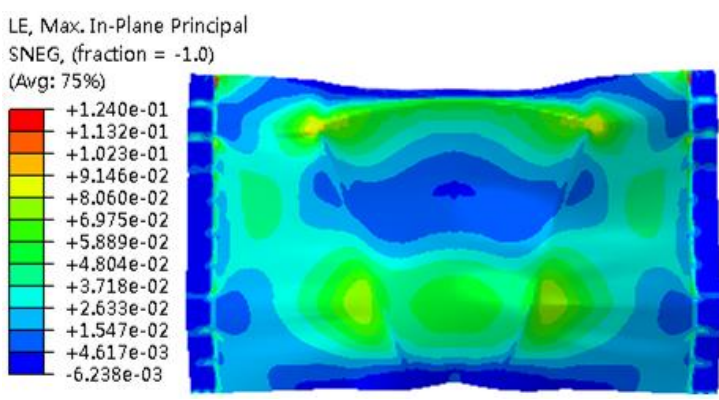

$\mathrm{a}$

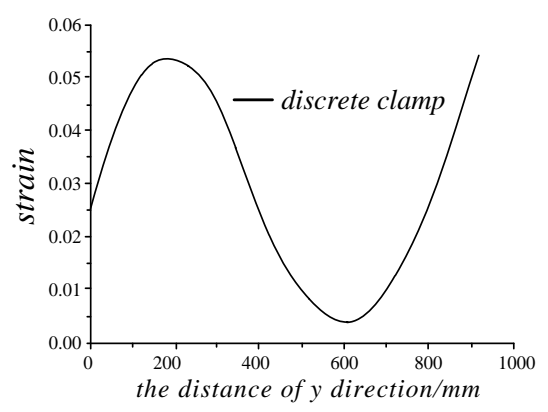

b

Fig. 13 The strain distribution of high flexible stretch formed part: a) the strain distribution; b) the strain distribution of y direction 
Fig. 14 shows the thickness distribution of the double curved top part. As shown in the figure, the maximum and the minimum thickness in the effective forming zone of the formed part is $1.495 \mathrm{~mm}$ and $1.441 \mathrm{~mm}$ respectively, and the maximum thinning rate is $3.93 \%$ within the allowable range. As shown in Fig. 14, b, the thickness decreases first, then increase and then decreases along the $y$ direction, which is contrary to the trend of strain distribution.

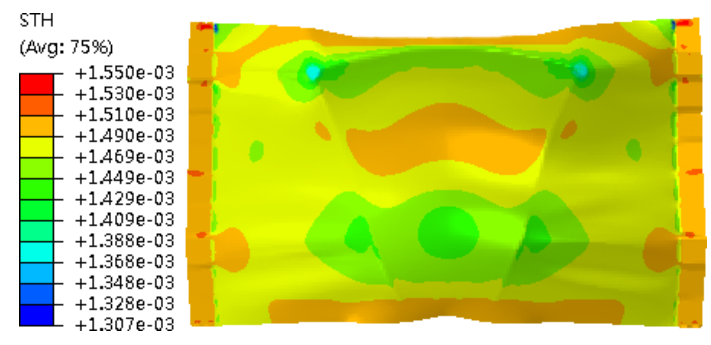

a

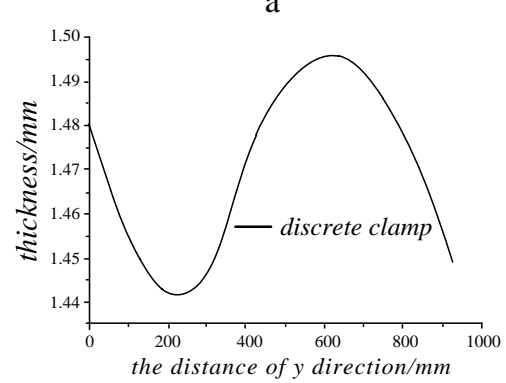

b

Fig. 14 The thickness distribution of high flexible stretch formed parts: a) the thickness distribution; b) the thickness distribution of $\mathrm{y}$ direction

\subsection{Forming test}

The forming test of the double curved top part is carried out with the discrete clamp stretch forming device in Fig. 9, a. The material and size of die and sheet metal are the same as those of numerical simulation. The test part is shown in Fig. 15. As shown in the figure, the forming effect is good in the effective forming zone of the formed part, and there is no wrinkling. The forming results are consistent with the numerical simulation results.

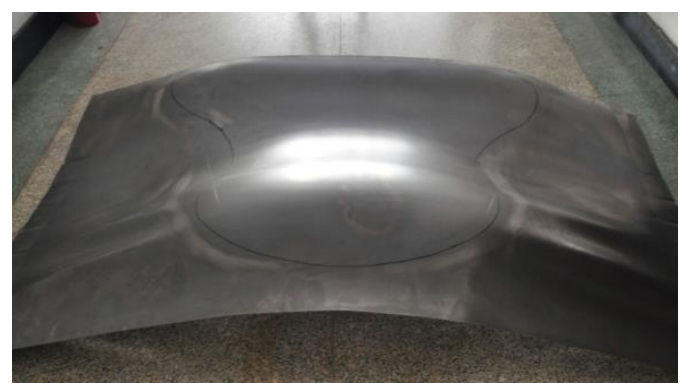

Fig. 15 The double curved top part (discrete clamp)

\section{Conclusions}

1. The research results of the trapezoidal profile part show that: the discrete clamp can be distributed with the curvature change of the die edge, so that the integral displacement of the traditional clamp is avoided, it is easier for the sheet metal to fit the die, the strain and thickness of the part are more uniform, and the forming effect is better.
2. The research results of the double curved top part show that: during the forming process of the integral clamp, synchronous displacement is produced in all parts, and the curved part with convex and concave curvature change cannot be formed, and the sheet metal is faced with the risk of cracking. The discrete clamp can adapt to the curvature change distribution of the die, so that the sheet metal can fit the complex die profile. the strain and thickness of the part are more uniform, and the forming quality is high.

3. The discrete clamp stretch forming tests are conducted for the trapezoidal profile part and the double curved top part. The results show that the forming effect is good and the forming trend is consistent with the numerical simulation results, which verifies the correctness of the numerical simulation process.

4. The research results show that it is feasible to form complex curved parts with the discrete clamp stretch forming method, which expands the application scope of the stretch forming device.

\section{Funding}

The work was funded by Major Technological Project of Jilin Institute of Chemical Technology, China (2019017) and Jilin Institute of Chemical Technology Doctor Scientific Research Starting Foundation, China (2021023).

\section{References}

1. Sun, L. R.; Cai, Z. Y.; Li, X. J. 2019. Research on contact state and its effect on forming precision in uniform-contact stretch forming based on loading at multiposition, Metals 9. http://dx.doi.org/10.3390/ met9070719.

2. Abosaf, M.; Essa, K.; Alghawail, A.; Tolipov, A.; Su. S. Z.; Pham. D. 2017. Optimisation of multi-point forming process parameters, Int. J. Adv. Manuf. Tech. 92: 1849-1859. http://dx.doi.org/10.1007/s00170-017-0155 -y.

3. Wang, Y.; Liu, D. Z.; Li, R. 2019. Numerical investigation for the flexible stretch-stamp forming process of sheet metal, Adv Mech Eng. 11: 1-11. http: // dx. doi. org / 10.1177/1687814018819287.

4. Xing, J.; Cheng, Y. Y.; Yi, Z. 2019. Stress-strain and form accuracy of carbon steel components produced by a multi-point stretch forming technique, Strength of Materials 51: 667-677. http://dx.doi.org/ 10. 1007 / s11223-019-00114-4.

5. Wang, S. H.; Cai, Z. Y.; Li, M. Z. 2010. Numerical investigation of the influence of punch element in multi-point stretch forming process, Int. J. Adv. Manuf. Tech. 49: 475-483. http://dx.doi.org/ 10.1007/ s00170-009-2420-1.

6. Xing, J.; Cheng, Y. Y.; Yi, Z. 2019. The effect of swinging ball heads with different arrangements in multi-point stretch-forming process, Materials 12: 337. http://dx.doi.org/ 10.3390/ma12030337.

7. Kuboki, T.; Jin, Y.; Murata, M. 2012. Prediction of stress-strain diagram from forming load in stretch forming, Int. J. Mech. Sci. 60: 46-53. http://dx.doi.org/ 10.1016/j.ijmecsci.2012.04.005.

8. Wang, Y.; Li, M. Z.; Wang, D. M.; Wang, A. Y. 
2014. Modeling and numerical simulation of multigripper flexible stretch forming process, Int. J. Adv. Manuf. Tech. 73: 279-288.

http://dx.doi.org/ 10.1007/s00170-014-5794-7.

9. Yu, J. Q.; Li, Y.; Teng, F.; Liang, J. C.; Lin, X. F.; Liang, C.; Chen, G. Y.; Sun, G. P. 2018. Research on the cross section forming quality of three-dimensional multipoint stretch forming parts, Adv. Mater. Sci. Eng. 2018: 1-11. http://dx.doi.org/10.1155/2018/4265617.

10. Yang, Z.; Cai, Z.Y.; Che, C.J. Li, M. Z. 2016. Numerical simulation research on the loading trajectory in stretch forming process based on distributed displacement loading, Int. J. Adv. Manuf. Tech. 82: 1353-1362. http://dx.doi.org/10.1007/s00170-015-7470-y.

11. Wang, Y.; Li, M. Z.; Peng, H.; L. 2014. Study on transition length in multi-gripper flexible stretch forming process, J. Mech. Eng. 10: 72-79. http://dx.doi.org/ 10.3901/JME.2014.10.072.
Y. Y. Cheng, J. Xing, B. Y. Zhang

\section{RESEARCH ON STRETCH FORMING PROCESS OF THE DISCRETE CLAMP FOR COMPLEX CURVED PARTS}

\section{S u m m a r y}

The discrete clamp is used to replace the integral clamp in the traditional stretch forming process, and the stretch forming process of complex curved parts is studied. With the trapezoidal profile part and the double curved top part as the research objects, numerical simulation of the stretch forming process with the integral clamp and the discrete clamp is carried out respectively. The numerical simulation results show that: compared with the integral clamp, it is easier for the trapezoidal profile part to fit the die during stretch forming with the discrete clamp, and the distribution of strain and thickness of the formed part is more uniform; during forming of the double curved top part, with the same forming force, the sheet metal cannot fit the die completely with the integral clamp forming, while it can completely fit the die during stretch forming with the discrete clamp. When the forming force of the integral clamp is increased, the sheet metal still cannot fit the die completely, and the sheet metal is more likely to crack. Stretch forming tests are conducted for the trapezoidal profile part and the double curved top part with the discrete clamp stretch forming device, and good forming effect is realized, which is consistent with the numerical simulation results.

Keywords: discrete clamp; stretch forming; numerical simulation; complex curved parts.

Received November 16, 2020 Accepted February 04, 2022 